\title{
Intracoronary thrombolysis in evolving myocardial infarction
}

\section{Sequential angiographic analysis of left ventricular performance}

\author{
A CRIBIER, J BERLAND, O CHAMPOUD, N MOORE, P BEHAR, B LETAC \\ From the Service des Soins Intensifs Cardiologiques et des Explorations Hémodynamiques Cardiovasculaires, Centre \\ Hospitalier Universitaire, Hôpital Charles Nicolle, Rouen, France
}

SUMMARY Since November 1979 left ventricular angiography and coronary arteriography have been performed in 80 patients with evolving acute myocardial infarction in order to attempt coronary recanalisation by local streptokinase infusion. The average delay between the onset of symptoms and streptokinase infusion was 3.6 hours. Thrombolysis was successful in $64 \%$ of cases. No serious complications related to the procedure were noted. Of the 12 patients in cardiogenic shock, recanalisation was achieved in only four, of whom two survived.

To evaluate the left ventricular salvage resulting from early recanalisation the last 58 patients had a second left ventricular angiogram and further coronary arteriograms $21 \pm 10$ days later and 16 patients had a third study three months later. From the left ventricular angiogram in the right anterior oblique projection the ejection fraction and two graphic variables of regional wall motion were computed quantifying the hypokinetic zone. Patients were divided into two groups, according to the patency of the infarct related artery at the second control: group 1 consisted of 28 patients with successful recanalisation confirmed, and group 2 of 30 patients in whom no recanalisation was achieved or secondary reocclusion had occurred. At the second study the ejection fraction was unchanged in group 1 but had significantly decreased in group 2. Regional wall motion improved in group 1 and worsened in group 2, more so in patients without recanalisation than in those in whom secondary reocclusion had occurred. The third study showed a further decrease in ejection fraction in group 2. A progressive decrease in percentage residual stenosis was observed in group 1.

This sequential angiographic study confirms the partial myocardial salvage resulting from early coronary recanalisation during acute myocardial infarction.

Animal experiments have shown that the reperfusion of an obstructed coronary artery within the first six hours of coronary occlusion results in a reduced infarct size. ${ }^{1-3}$ In man, since the first report by Rentrop et al. ${ }^{4}$ four years ago, it has been widely shown that the intracoronary infusion of fibrinolytic drugs can produce coronary artery recanalisation..$^{5-12}$ and this has been proposed as a way of reducing the

Accepted for publication 3 May 1983 extent of acute myocardial infarction. The question, however, of how beneficial the restoration of coronary flow is in the salvage of jeopardised myocardium remains unclear and warrants further investigations.

Eighty patients at the early stage of myocardial infarction were considered for myocardial reperfusion by intracoronary infusion of streptokinase and therefore had left ventricular and coronary angiograms. Fifty eight of these patients had a second haemodynamic and angiographic study three weeks after the intervention to assess the natural history of their left ventricular performance, and $16 \mathrm{had}$ a third 
study three months later. Left ventricular function and, in particular, regional wall motion were studied at the chronic stage of infarction in the case of successful and unsuccessful intracoronary thrombolysis to assess the effect of early coronary recanalisation.

\section{Subjects and methods}

Beginning in November 1979, patients admitted with an acute myocardial infarction of less than six hours were considered for intracoronary thrombolysis. Diagnostic criteria were typical chest pain lasting more than 30 minutes, which was unresponsive to sublingual glyceryl trinitrate, and ST segment elevation of more than $2 \mathrm{~mm}$ in at least two leads in the electrocardiogram, with or without a $Q$ wave. The classical contraindications to streptokinase infusion precluded entry to the trial in only two patients. Informed consent was obtained in all cases.

There were 80 patients ( 70 men and 10 women) with a mean age of 56 years (range 30-77). The mean delay between the onset of chest pain and admission was two hours and 20 minutes (30 minutes to six hours). Four patients had had a previous myocardial infarction. Twelve patients were in cardiogenic shock.

\section{Procedure}

Where possible initial treatment was limited to morphine only for pain. Intravenous glyceryl trinitrate was always avoided. In some cases intravenous atropine, dopamine, or lignocaine were administered. After catheterisation by the femoral route, a right anterior oblique left ventricular angiogram was performed, followed by angiography of only the affected coronary artery in almost every case as determined from the electrocardiogram and left ventricular angiographic data.

Intracoronary thrombolysis was not attempted in nine patients: in two in whom the coronary ostium could not be selectively catheterised; in four of the six patients whose arterial obstruction was incomplete; and in three patients in whom no coronary lesion could be seen on the screen during injections or on video tape replay.

Coronary recanalisation was attempted in the other 71 patients: glyceryl trinitrate, $0.30 \mathrm{mg}$, was injected into the obstructed coronary artery to rule out spasm. A soft tipped straight metallic guide wire was then inserted into the coronary artery in order to pass the occlusion whenever possible. After an intravenous injection of dexamethasone $(8 \mathrm{mg})$, a bolus of 5000 to $10000 \mathrm{IU}$ of streptokinase was selectively injected into the occluded artery. Streptokinase was thereafter infused at the rate of 2000 to $4000 \mathrm{IU} / \mathrm{min}$, usually through the coronary angiography catheter. In 13 cases streptokinase was infused through a $2 \mathrm{~F}$ radioopaque catheter advanced through the angiography catheter into the coronary artery to the site of the obstruction. The effect of streptokinase was assessed with an electrocardiogram and coronary opacification every 15 minutes. After successful recanalisation, streptokinase infusion was continued for 15 to 30 minutes longer. If recanalisation was not achieved after 60 minutes, the procedure was usually stopped; in two cases, however, the infusion was continued for a further 30 and 60 minutes.

At the end of the procedure the patients were transferred to the coronary care unit. Treatment consisted of heparin, started when the hourly checked plasma fibrinogen concentration was above $150 \mathrm{mg} / 100 \mathrm{ml}$, intravenous glyceryl trinitrate $10 \mu \mathrm{g} / \mathrm{min}$ for 24 hours, nifedipine $30 \mathrm{mg} /$ day orally, and dipyridamole 450 $\mathrm{mg} /$ day orally. Antiarrhythmic drugs were used whenever necessary. The patients' progress was followed by continuous electrocardiographic monitoring and a standard electrocardiogram twice a day with MB CK assays every six hours. They were usually discharged after two weeks taking nifedipine, dipyridamole, and oral anticoagulants in all cases.

EVALUATION OF SUCCESS AND PATIENT GROUPS In the last 58 consecutive patients, a second catheterisation (right anterior oblique left ventricular angiogram and full coronary angiogram) was done 10 to 45 days (mean $21 \pm 10$ days) after the initial examination. The patients were divided into two groups according to the patency of the initially obstructed artery. Group 1 consisted of 28 patients in whom the coronary artery had been recanalised and was patent at the second study. Group 2 consisted of 30 patients in whom the coronary artery involved was occluded at the second study, either because of secondary reocclusion after an initially successful recanalisation (group 2a, 10 patients), or because the thrombolysis was unsuccessful, or lysis was not attempted (group 2b, 20 patients).

The evolution of myocardial function was studied by comparative analysis of the left ventricular angiograms obtained initially and during the second catheterisation.

In 16 patients (seven from group 1 and nine from group 2) a third identical investigation was done three months later, to study the chronic evolution of the left ventricular function. In these patients, the residual coronary stenosis (percentage diameter narrowing) was measured at each of the three studies.

\section{ANGIOGRAPHIC DATA ANALYSIS}

End-systolic and end-diastolic left ventricular volumes (Simpson's rule) and the ejection fraction were 


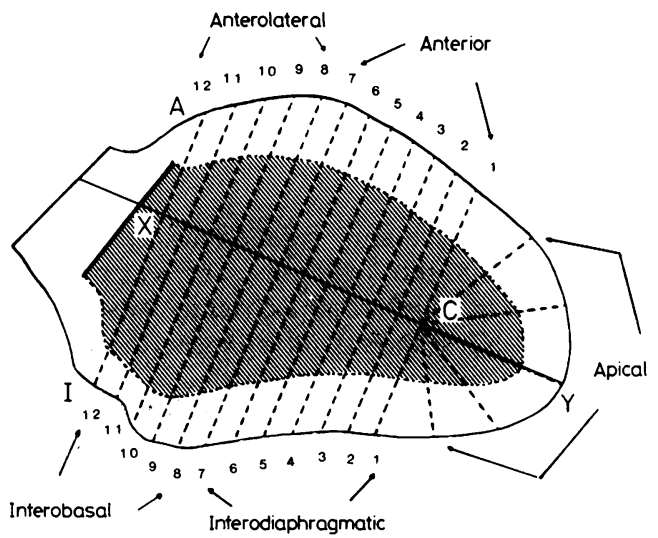

Fig. 1 Regional wall motion. The left ventricular systolic and diastolic outlines were matched according to Leighton's method. Point $C$ is two-thirds of the distance from $X$ to $Y$ on the major axis. Twelve equidistant axes perpendicular to the major axis are drawn from point $X$ to point $C$ to study the wall motion in the following regions: anterolateral ( $A 12$ to $A$ 8), anterior ( $A 8$ to $A$ 1), inferobasal (I 12 to I 7), and inferior (I 7 to I I). The apex was studied by five radiating axes $\left(15^{\circ}\right.$ steps) centred on point $C$.

computed from each left ventricular angiogram. Regional wall motion was studied from a superposition of systolic and diastolic left ventricular outlines with a correction for apex rotation, according to the method of Leighton et al. ${ }^{13}$ The ventricular cavity was divided into 30 segments by 29 axes (Fig. 1). The percentage change in each axis was compared with the theoretically normal values derived from the study of 20 normal subjects and the regional contractility was expressed as a linear graph (Fig. 2) in which the upper and lower limits of normal (mean $\pm 2 \mathrm{SD}$ ) are shown. Hypokinesis was considered when the percentage shortening of an axis was more than 2SD below normal mean. To evaluate the importance of the hypokinetic zone and compare successive angiograms, two indices were computed from the graphic wall motion outline (Fig. 3): the surface limited by the studied patient's curve and the lower limit of normal values was planimetered and this so-called "hypokinetic surface" was expressed in $\mathrm{cm}^{2}$. A so-called "hypokinetic length" was defined as the percentage of the total circumference which was considered hypokinetic on the graphic representation. These two variables give an estimation of the importance of the hypokinetic zone, though they obviously cannot be considered as the true physical measure of this zone. Results are given as mean \pm SD.

Statistical analysis was done using Student's $t$ test as applied to paired and unpaired data.

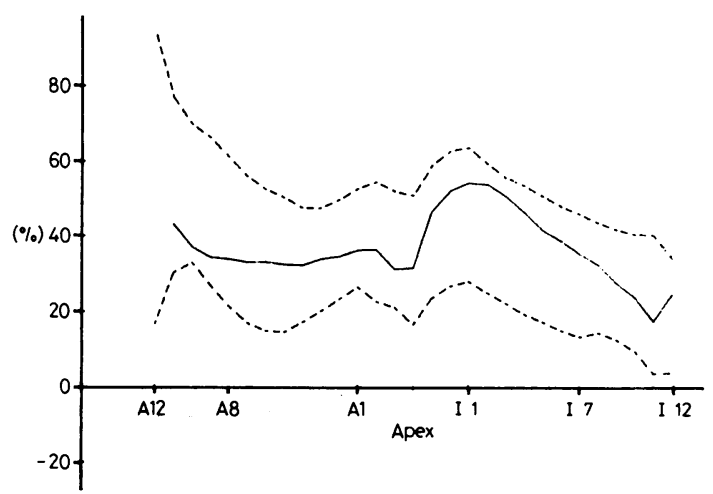

Fig. 2 Normal regional wall motion. On the vertical axis is shown the percentage shortening of the axes; and on the horizontal axis, the number of each axis. A normal wall motion curve (solid line) remains within the limits set by normal mean \pm 2 $S D$ (dashed lines).
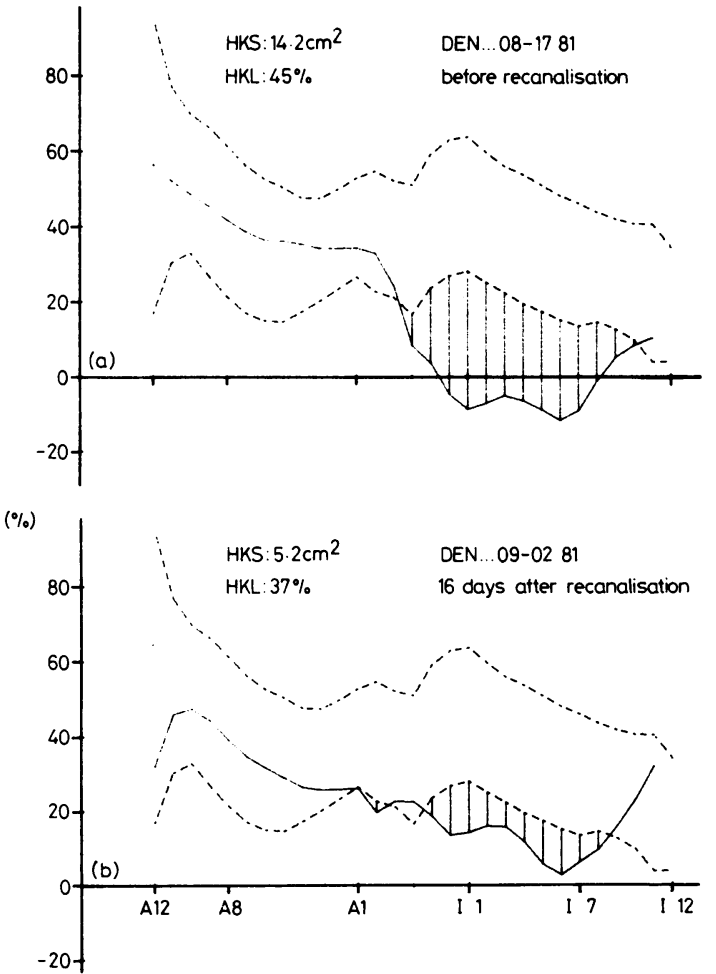

Fig. 3 Wall motion before and 16 days after successful recanalisation of a right coronary artery in a patient with inferior myocardial infarction. Upper panel, before recanalisation, the regional wall motion curve crosses the lower limit of normal and limits with it a "hypokinetic surface" (hatched) which is planimetered (hypokinetic surface $(H K S)=14.2 \mathrm{~cm}^{2}$ ). The measured length of the hypokinetic segment (HKL) is $45 \%$ of measured total left ventricular circumference.

Lower panel, at the second control, HKS has decreased by $63 \%$ to $5 \cdot 2 \mathrm{~cm}^{2}$ and $H K L$ by $18 \%$ to $37 \%$. 


\section{Results}

\section{CORONARY ANGIOGRAPHIC DATA}

Coronary angiography was performed $3.6 \pm 1 \cdot 2$ hours after the onset of chest pain. It showed complete coronary occlusion in all patients except six in whom there was only a severe stenosis ( $92 \%$ of cases). The left coronary artery was affected in 50 patients (left main, 4; left anterior descending, 32; circumflex, 12; diagonal, two) and the right coronary artery in 30 patients. Intracoronary glyceryl trinitrate had no effect except in two cases where it was followed by a transient reopacification of the first centimetres of the artery. The guide wire could be pushed through the obstruction in 32 cases, with a subsequent sluggish and incomplete opacification of the occluded artery, often showing unmistakable evidence of intravascular thrombosis at the occlusion site.

Satisfactory recanalisation was obtained by intracoronary streptokinase in 39 out of $61(64 \%)$ patients whose coronary artery was occluded and in whom the complete procedure was applied. The mean perfusion time was 50 minutes (20-120 minutes) and varied according to the quality of the recanalisation and the patient's clinical status. The mean infused dose of streptokinase was 180000 IU (40000 to 280000 ). After recanalisation, a greater than $50 \%$ stenosis (visual estimation) was observed at the site of the obstruction in all cases.

\section{CLINICAL COURSE}

In cases of successful recanalisation, a striking improvement in the symptoms and electrocardiographic signs of myocardial ischaemia was observed, the elevated ST segments returning to the isoelectric line within a few minutes. Ventricular extrasystoles were frequent during the first few minutes after recanalisation but were easily controlled by intravenous lignocaine. Six patients had ventricular tachycardia which had to be cardioverted.

Of the 12 patients with cardiogenic shock on admission, eight died during the procedure, in two cases despite recanalisation. These patients had left main occlusion in four instances (in two cases recanalisation was attempted during artificial ventilation and heart massage) and a proximal left anterior descending artery occlusion in four cases. Of the 4 other patients with cardiogenic shock, recanalisation was not achieved in two who died within 48 hours after admission; the two other patients in whom recanalisation

Table 1 Individual values of group 1 (successful confirmed recanalisation)

\begin{tabular}{|c|c|c|c|c|c|c|c|c|c|c|c|c|c|}
\hline \multirow[t]{2}{*}{ Cases } & \multicolumn{2}{|c|}{$H R$ (beats/min) } & \multicolumn{2}{|c|}{$L V E D P(m m H g)$} & \multicolumn{2}{|c|}{$L V E D V\left(\mathrm{ml} / \mathrm{m}^{2}\right)$} & \multicolumn{2}{|c|}{$E F(\%)$} & \multicolumn{2}{|c|}{$H K S\left(\mathrm{~cm}^{2}\right)$} & \multicolumn{2}{|c|}{$H K L(\%)$} & \multirow{2}{*}{$\begin{array}{l}\text { Coronary } \\
\text { artery }\end{array}$} \\
\hline & Base & 2nd $E x$ & Base & 2nd $E x$ & Base & 2nd $E x$ & Base & 2nd $E x$ & Base & 2nd $E x$ & Base & 2nd $E x$ & \\
\hline $\begin{array}{l}1 \\
2 \\
3 \\
4 \\
5 \\
6 \\
7 \\
8 \\
9 \\
10 \\
11 \\
12 \\
13 \\
14 \\
15 \\
16 \\
17 \\
18 \\
19 \\
20 \\
21 \\
22 \\
23 \\
24 \\
25 \\
26 \\
27 \\
28 \\
M \\
\text { MD }\end{array}$ & $\begin{array}{r}97 \\
90 \\
92 \\
94 \\
86 \\
86 \\
120 \\
77 \\
54 \\
64 \\
100 \\
63 \\
92 \\
91 \\
86 \\
88 \\
80 \\
110 \\
81 \\
80 \\
103 \\
80 \\
90 \\
60 \\
105 \\
62 \\
100 \\
63 \\
86 \\
16\end{array}$ & $\begin{array}{r}110 \\
100 \\
80 \\
90 \\
65 \\
97 \\
67 \\
71 \\
70 \\
61 \\
94 \\
93 \\
59 \\
90 \\
73 \\
67 \\
60 \\
100 \\
107 \\
86 \\
94 \\
78 \\
87 \\
86 \\
101 \\
92 \\
100 \\
63 \\
84 \\
16 \\
5\end{array}$ & $\begin{array}{r}15 \\
8 \\
16 \\
25 \\
25 \\
18 \\
15 \\
8 \\
15 \\
25 \\
18 \\
12 \\
20 \\
20 \\
20 \\
15 \\
20 \\
40 \\
15 \\
15 \\
25 \\
16 \\
14 \\
14 \\
35 \\
10 \\
22 \\
20 \\
19 \\
7 \\
n\end{array}$ & $\begin{array}{r}12 \\
5 \\
25 \\
22 \\
13 \\
12 \\
11 \\
17 \\
12 \\
15 \\
25 \\
12 \\
18 \\
20 \\
10 \\
14 \\
8 \\
40 \\
10 \\
10 \\
10 \\
8 \\
5 \\
30 \\
10 \\
5 \\
14 \\
12 \\
14 \\
8 \\
0\end{array}$ & $\begin{array}{r}70 \\
105 \\
76 \\
120 \\
73 \\
103 \\
80 \\
63 \\
126 \\
103 \\
104 \\
89 \\
72 \\
56 \\
62 \\
80 \\
71 \\
112 \\
117 \\
101 \\
101 \\
108 \\
94 \\
70 \\
72 \\
81 \\
63 \\
78 \\
88 \\
20 \\
\mathbf{N} \\
\end{array}$ & $\begin{array}{r}88 \\
78 \\
100 \\
125 \\
79 \\
110 \\
84 \\
110 \\
138 \\
96 \\
99 \\
92 \\
91 \\
86 \\
97 \\
89 \\
106 \\
132 \\
89 \\
93 \\
80 \\
67 \\
93 \\
87 \\
68 \\
91 \\
72 \\
98 \\
94 \\
17\end{array}$ & $\begin{array}{l}53 \\
40 \\
53 \\
35 \\
41 \\
60 \\
48 \\
44 \\
49 \\
52 \\
45 \\
65 \\
32 \\
50 \\
41 \\
50 \\
48 \\
21 \\
41 \\
37 \\
35 \\
64 \\
63 \\
55 \\
47 \\
41 \\
54 \\
59 \\
47 \\
10\end{array}$ & $\begin{array}{l}56 \\
45 \\
51 \\
32 \\
41 \\
58 \\
51 \\
41 \\
55 \\
59 \\
47 \\
57 \\
57 \\
41 \\
56 \\
50 \\
32 \\
20 \\
44 \\
43 \\
48 \\
58 \\
59 \\
40 \\
50 \\
62 \\
59 \\
59 \\
49 \\
10\end{array}$ & $\begin{array}{r}20 \\
10 \\
11 \\
18 \\
10 \\
10 \\
9 \\
10 \\
14 \\
18 \\
9 \\
11 \\
22 \\
11 \\
20 \\
7 \\
14 \\
23 \\
24 \\
16 \\
3 \\
5 \\
12 \\
6 \\
8 \\
8 \\
1 \\
12 \\
6 \\
0<0\end{array}$ & $\begin{array}{r}15 \\
6 \\
6 \\
14 \\
6 \\
8 \\
9 \\
13 \\
5 \\
8 \\
9 \\
5 \\
4 \\
15 \\
12 \\
10 \\
18 \\
16 \\
18 \\
11 \\
3 \\
4 \\
12 \\
13 \\
1 \\
6 \\
4 \\
9 \\
5 \\
.01\end{array}$ & $\begin{array}{l}40 \\
45 \\
50 \\
55 \\
54 \\
42 \\
41 \\
44 \\
45 \\
45 \\
53 \\
42 \\
64 \\
51 \\
40 \\
38 \\
53 \\
5 \\
74 \\
74 \\
56 \\
75 \\
20 \\
3\end{array}$ & $\begin{array}{r}31 \\
29 \\
30 \\
57 \\
45 \\
45 \\
38 \\
44 \\
37 \\
43 \\
53 \\
36 \\
16 \\
48 \\
39 \\
44 \\
60 \\
61 \\
46 \\
45 \\
28 \\
30 \\
50 \\
47 \\
6 \\
36 \\
31 \\
40 \\
13 \\
.05\end{array}$ & $\begin{array}{l}\text { LCx } \\
\text { RCA } \\
\text { RCA } \\
\text { LAD } \\
\text { RCA } \\
\text { RCA } \\
\text { RCA } \\
\text { LAD } \\
\text { RCA } \\
\text { LAD } \\
\text { LAD } \\
\text { LCx } \\
\text { LAD } \\
\text { LAD } \\
\text { RCA } \\
\text { RCA } \\
\text { LAD } \\
\text { LAD } \\
\text { RCA } \\
\text { LAD } \\
\text { LAD } \\
\text { LAD } \\
\text { LCx } \\
\text { LAD } \\
\text { LAD } \\
\text { LAD } \\
\text { LAD } \\
\text { RCA }\end{array}$ \\
\hline
\end{tabular}

LAD left anterior descending artery; LCx, left circumflex artery; RCA, right coronary artery; EF, ejection fraction; HKL, hypokinetic length; HKS, hypokinetic surface; HR, heart rate; LVEDP, left ventricular end-diastolic pressure; LVEDV, left ventricular end-diastolic volume; Base, before recanalisation; $2 \mathrm{nd} \mathrm{Ex}$, second study, 10 to 45 days after recanalisation. 
Intracoronary thrombolysis in evolving myocardial infarction

Table 2 Individual values of group $2 a$ (recanalised patients with secondary reocclusion) and group $2 b$ (no recanalisation)

\begin{tabular}{|c|c|c|c|c|c|c|c|c|c|c|c|c|c|c|}
\hline \multirow[t]{2}{*}{ Group } & \multirow[t]{2}{*}{ Pts } & \multicolumn{2}{|c|}{$H R$ (beats/min) } & \multicolumn{2}{|c|}{$L V E D P(\mathrm{mmHg})$} & \multicolumn{2}{|c|}{$L V E D V\left(\mathrm{ml} / \mathrm{m}^{2}\right)$} & \multicolumn{2}{|c|}{$E F(\%)$} & \multicolumn{2}{|c|}{$H K S\left(\mathrm{~cm}^{2}\right)$} & \multicolumn{2}{|c|}{$H K L(\%)$} & \multirow{2}{*}{$\begin{array}{c}\text { Coronary } \\
\text { artery }\end{array}$} \\
\hline & & Base & 2nd $E x$ & Base & 2nd $E x$ & Base & $2 n d E x$ & Base & $2 n d E x$ & Base & $2 n d E x$ & Base & 2nd $E x$ & \\
\hline $\begin{array}{l}2 a \\
n=10\end{array}$ & $\begin{array}{l}1 \\
2 \\
3 \\
4 \\
5 \\
6 \\
7 \\
8 \\
9 \\
10 \\
\text { Mean } \\
\text { SD } \\
\text { p }\end{array}$ & $\begin{array}{r}77 \\
97 \\
91 \\
70 \\
109 \\
94 \\
60 \\
62 \\
80 \\
91 \\
83 \\
16\end{array}$ & $\begin{array}{r}81 \\
70 \\
71 \\
92 \\
72 \\
82 \\
64 \\
73 \\
67 \\
105 \\
78 \\
13 \\
\text { NS }\end{array}$ & $\begin{array}{r}15 \\
12 \\
12 \\
20 \\
12 \\
20 \\
16 \\
14 \\
6 \\
18 \\
15 \\
4 \\
\mathrm{~N}\end{array}$ & $\begin{array}{r}17 \\
10 \\
10 \\
20 \\
12 \\
25 \\
8 \\
13 \\
15 \\
8 \\
14 \\
6\end{array}$ & $\begin{array}{c}92 \\
72 \\
65 \\
123 \\
74 \\
66 \\
79 \\
60 \\
90 \\
78 \\
80 \\
18 \\
\mathrm{p}<\end{array}$ & $\begin{array}{r}105 \\
110 \\
68 \\
136 \\
94 \\
86 \\
88 \\
138 \\
107 \\
87 \\
102 \\
22 \\
0.02\end{array}$ & $\begin{array}{l}50 \\
45 \\
64 \\
50 \\
58 \\
62 \\
46 \\
38 \\
48 \\
57 \\
52 \\
8 \\
\\
\mathrm{~N}\end{array}$ & $\begin{array}{r}47 \\
47 \\
51 \\
34 \\
47 \\
58 \\
51 \\
32 \\
45 \\
60 \\
47 \\
9\end{array}$ & $\begin{array}{r}9 \\
10 \\
5 \\
8 \\
6 \\
1 \\
5 \\
10 \\
13 \\
9 \\
8 \\
3 \\
\\
\mathrm{~N}\end{array}$ & $\begin{array}{r}7 \\
14 \\
7 \\
16 \\
7 \\
2 \\
11 \\
13 \\
9 \\
6 \\
9 \\
4\end{array}$ & $\begin{array}{c}32 \\
38 \\
26 \\
48 \\
30 \\
11 \\
33 \\
47 \\
40 \\
37 \\
34 \\
11 \\
\mathrm{p}<\end{array}$ & $\begin{array}{l}37 \\
46 \\
27 \\
48 \\
28 \\
22 \\
41 \\
55 \\
56 \\
35 \\
40 \\
12 \\
0.05\end{array}$ & $\begin{array}{l}\text { RCA } \\
\text { RCA } \\
\text { D } \\
\text { RCA } \\
\text { RCA } \\
\text { RCA } \\
\text { LCx } \\
\text { LAD } \\
\text { RCA } \\
\text { RCA }\end{array}$ \\
\hline $\begin{array}{l}2 a+2 b \\
n=30\end{array}$ & $\begin{array}{l}1 \\
2 \\
3 \\
4 \\
5 \\
6 \\
7 \\
8 \\
9 \\
10 \\
11 \\
12 \\
13 \\
14 \\
15 \\
16 \\
17 \\
18 \\
19 \\
20 \\
\text { Mean } \\
\text { SD } \\
\text { p } \\
\text { Mean } \\
\text { SD } \\
\text { p }\end{array}$ & $\begin{array}{r}83 \\
115 \\
59 \\
92 \\
83 \\
85 \\
72 \\
73 \\
71 \\
82 \\
84 \\
107 \\
110 \\
67 \\
58 \\
143 \\
125 \\
64 \\
62 \\
69 \\
86 \\
23 \\
1 \\
85 \\
21 \\
1\end{array}$ & $\begin{array}{r}117 \\
64 \\
71 \\
74 \\
66 \\
86 \\
78 \\
65 \\
73 \\
92 \\
80 \\
90 \\
94 \\
90 \\
95 \\
82 \\
97 \\
80 \\
71 \\
75 \\
81 \\
13 \\
\text { NS } \\
80 \\
13 \\
\text { NS }\end{array}$ & $\begin{array}{r}20 \\
8 \\
12 \\
10 \\
10 \\
35 \\
24 \\
15 \\
15 \\
12 \\
12 \\
16 \\
30 \\
15 \\
15 \\
16 \\
25 \\
25 \\
15 \\
718 \\
7 \\
17 \\
6 \\
\quad \mathrm{~N}\end{array}$ & $\begin{array}{r}27 \\
30 \\
10 \\
8 \\
12 \\
30 \\
15 \\
20 \\
10 \\
20 \\
10 \\
12 \\
18 \\
25 \\
30 \\
8 \\
25 \\
10 \\
17 \\
5 \\
9 \\
16 \\
16 \\
8 \\
1 S\end{array}$ & $\begin{array}{r}132 \\
89 \\
121 \\
73 \\
74 \\
74 \\
82 \\
55 \\
96 \\
74 \\
58 \\
94 \\
74 \\
88 \\
98 \\
85 \\
54 \\
60 \\
129 \\
55 \\
83 \\
23 \\
\mathrm{p}< \\
82 \\
21 \\
\mathrm{p}<0\end{array}$ & $\begin{array}{r}100 \\
135 \\
103 \\
110 \\
98 \\
112 \\
85 \\
75 \\
89 \\
97 \\
93 \\
104 \\
93 \\
126 \\
94 \\
143 \\
60 \\
120 \\
106 \\
67 \\
101 \\
21 \\
<0.01 \\
101 \\
21 \\
0.001\end{array}$ & $\begin{array}{l}53 \\
47 \\
72 \\
65 \\
45 \\
38 \\
52 \\
67 \\
57 \\
56 \\
68 \\
53 \\
59 \\
56 \\
61 \\
36 \\
56 \\
47 \\
53 \\
69 \\
55 \\
10 \\
\mathrm{p}<0 \\
54 \\
9 \\
\mathrm{p}<0\end{array}$ & $\begin{array}{r}30 \\
28 \\
62 \\
56 \\
38 \\
33 \\
50 \\
58 \\
49 \\
49 \\
55 \\
36 \\
29 \\
42 \\
24 \\
28 \\
52 \\
30 \\
51 \\
65 \\
43 \\
13 \\
001 \\
45 \\
12 \\
.001\end{array}$ & $\begin{array}{c}5 \\
6 \\
2 \\
3 \\
18 \\
9 \\
9 \\
4 \\
10 \\
8 \\
9 \\
4 \\
11 \\
3 \\
716 \\
16 \\
6 \\
15 \\
2 \\
1 \\
7 \\
5 \\
\mathrm{p}<0 \\
7 \\
4 \\
\mathrm{p}<0\end{array}$ & $\begin{array}{r}14 \\
14 \\
3 \\
5 \\
20 \\
17 \\
5 \\
16 \\
10 \\
16 \\
13 \\
20 \\
16 \\
18 \\
6 \\
12 \\
4 \\
2 \\
12 \\
6 \\
.001 \\
11 \\
6 \\
.001\end{array}$ & $\begin{array}{l}26 \\
39 \\
21 \\
15 \\
55 \\
-32 \\
42 \\
34 \\
32 \\
32 \\
39 \\
53 \\
29 \\
53 \\
43 \\
61 \\
36 \\
11 \\
37 \\
14 \\
\mathrm{p}<0 \\
36 \\
13 \\
\mathrm{p}<0\end{array}$ & $\begin{array}{r}53 \\
53 \\
16 \\
30 \\
62 \\
37 \\
47 \\
54 \\
45 \\
29 \\
70 \\
60 \\
38 \\
56 \\
38 \\
86 \\
44 \\
18 \\
46 \\
18 \\
.001 \\
44 \\
16 \\
.001\end{array}$ & $\begin{array}{l}\text { LAD } \\
\text { LAD } \\
\text { LCx } \\
\text { RCA } \\
\text { RCA } \\
\text { LAD } \\
\text { LAD } \\
\text { RCA } \\
\text { LAD } \\
\text { LCx } \\
\text { LCx } \\
\text { LCx } \\
\text { LAD } \\
\text { RCA } \\
\text { LCx } \\
\text { LAD } \\
\text { LCx } \\
\text { RCA } \\
\text { RCA } \\
\text { D }\end{array}$ \\
\hline
\end{tabular}

D, diagonal artery. Other abbreviations as in Table 1.
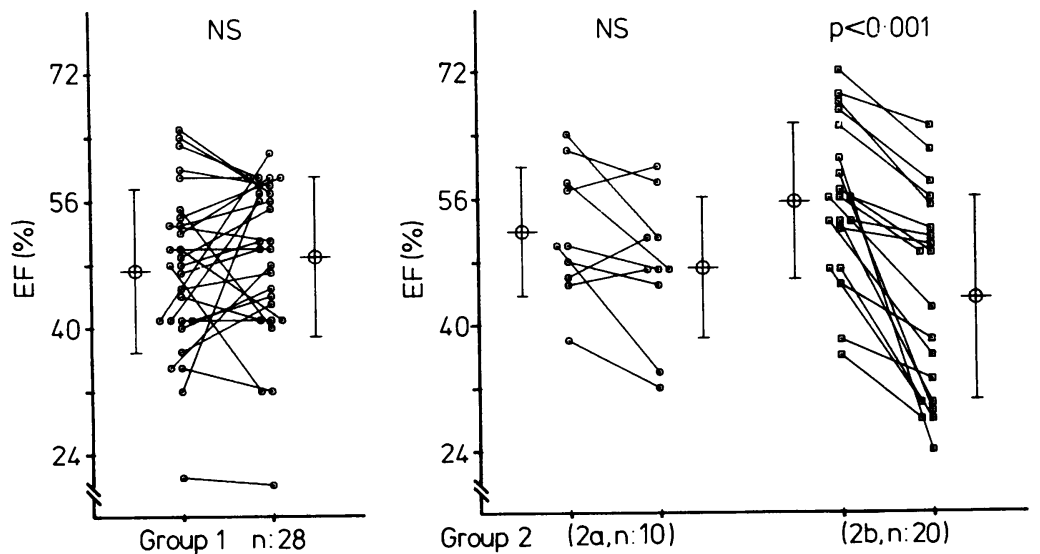

Fig. 4 Ejection fraction before and 15 to 45 days after intracoronary thrombolysis in group 1 on the left (successful confirmed recanalisation) and group 2 on the right (recanalisation with secondary reocclusion (2a), or no recanalisation (2b)).

Ejection fraction does not change in group 1 , but significantly worsens in group 2 (more in $2 b$ than $2 a$ ). 

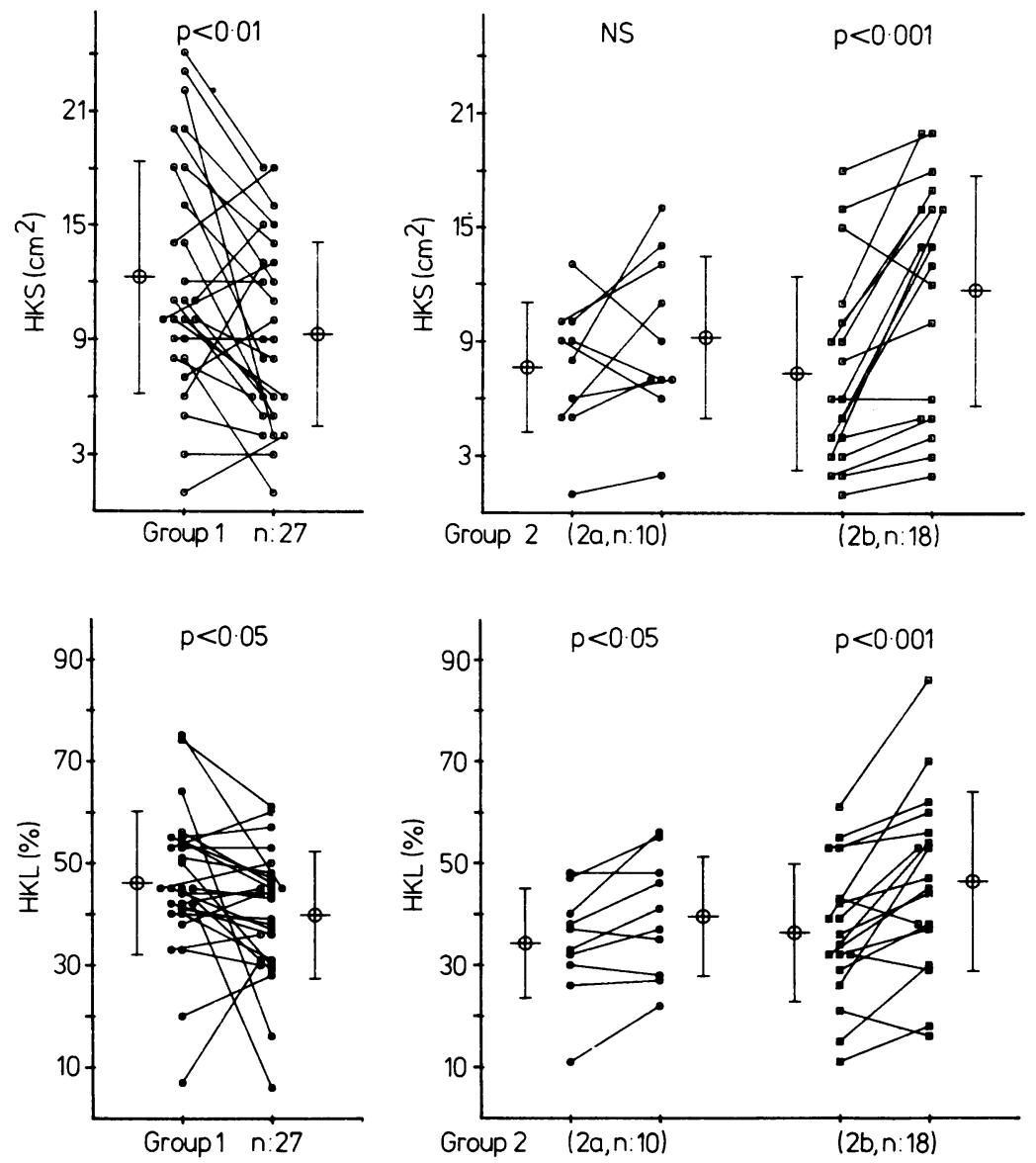

Fig.5 Regional wall motion indices before and 10 to 45 days after the recanalisation attempt. Upper panel, hypokinetic surface; lower panel, hypokinetic length (as \% of total left ventricular circumference).

Both variables decrease in group 1 (confirmed successful recanalisation) and increase in group 2 (secondary reocclusion after an initially successful recanalisation (group 2a)) and unsuccessful or no recanalisation (group 2b)).

was successful were alive and without symptoms 12 and 14 months later.

No complication directly related to the recanalisation procedure was noted.

Creatine kinase activity which was normal on admission $(<100 \mathrm{IU})$, increased to $1500 \pm 180 \mathrm{IU}$. Four patients in whom recanalisation was successful complained a few days later of chest pain with increased creatine kinase concentrations and electrocardiographic abnormalities suggesting extension of myocardial infarction. The second angiographic study showed coronary reocclusion in only two cases. There was no extension of myocardial infarction in patients in whom recanalisation was unsuccessful.

None of the 39 patients in whom recanalisation was successful died during the hospital stay, but two of the 22 patients in whom it was unsuccessful died.

\section{ANGIOGRAPHIC EVALUATION OF LEFT VENTRICULAR PERFORMANCE}

Comparison of first and second left ventricular angiograms Individual data are given in Tables 1 and 2 and in Figs. 4 and 5 . In one patient in group 1 and two patients in group 2 regional wall motion was not assessed because of a previous history of myocardial infarction.

Group 1: (successful confirmed recanalisation) 28 patients-There was no difference in the initial values of heart rate: $86 \pm 16 / \mathrm{mn} v 84 \pm 16 / \mathrm{mn}$ (NS), and left ventricular end-diastolic volume $88 \pm 20 \mathrm{ml} / \mathrm{m}^{2} v$ $94 \pm 17 \mathrm{ml} / \mathrm{m}^{2}$ (NS). Left ventricular end-diastolic 
Table 3 Third study, three months after initial assessment: individual values at each examination of seven patients in group 1 (successful recanalisation) and nine patients in group 2 (secondary reocclusion (2a) or no recanalisation (2b)) who had three haemodynamic studies

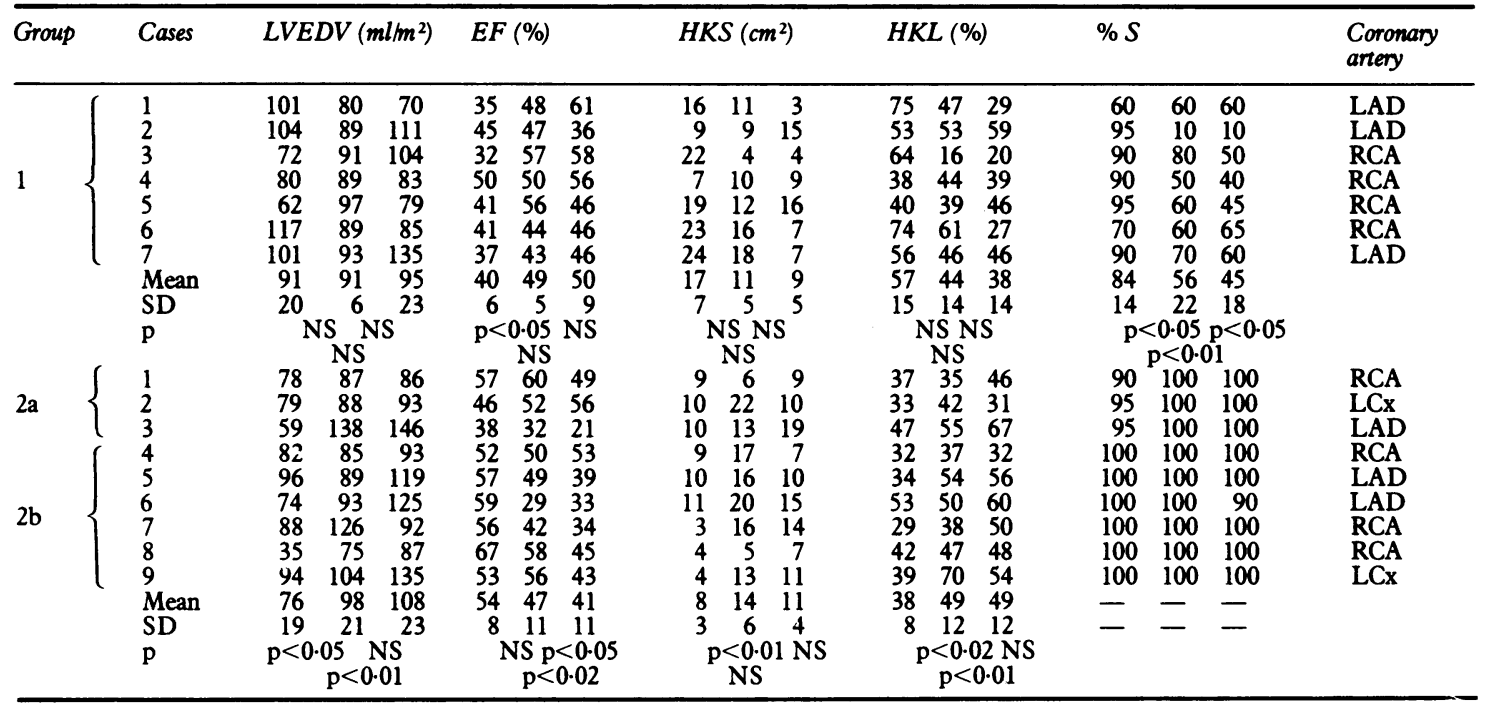

$\% \mathrm{~S}$, percent diameter narrowing on residual coronary stenosis. See Table 1 for other abbreviations.

pressure was decreased from $19 \pm 7 \mathrm{~mm} \mathrm{Hg}$ to $14 \pm 8$ $\mathrm{mmHg}(\mathrm{p}<0.02)$.

The ejection fraction was initially $47 \pm 10 \%$ (below $60 \%$ in 24 cases) and was unchanged at the second study $(49 \pm 10 \%$, NS). The hypokinetic surface decreased from $12 \pm 6 \mathrm{~cm}^{2}$ to $9 \pm 4 \mathrm{~cm}^{2}(\mathrm{p}<0.01)$ and the hypokinetic length from $46 \pm 14 \%$ to $40 \pm 12 \%$ $(p<0.05)$. In one out of 15 cases of proximal left anterior descending artery occlusion, a typical left ventricular aneurysm (defined as a protrusion of the akinetic surface out of the normal diastolic contour) was seen at the second study. In this patient there was a six hour delay between the onset of pain and recanalisation.

Group 2 (no recanalisation or reocclusion) 30 patientsThe heart rate $(85 \pm 21 / \mathrm{min} v 80 \pm 13 / \mathrm{min}$, NS) and left ventricular end-diastolic pressure $(17 \pm 6 \mathrm{mmHg} v$ $16 \pm 8 \mathrm{mmHg}$, NS) remained unchanged. The left ventricular end-diastolic volume increased from $82 \pm 21 \mathrm{ml} / \mathrm{m}^{2}$ to $101 \pm 21 \mathrm{ml} / \mathrm{m}^{2}(\mathrm{p}<0.001)$. The ejection fraction decreased from $54 \pm 9 \%$ to $45 \pm 12 \%$ $(p<0.001)$. In eight cases, the initially subnormal ejection fraction was much decreased, below $40 \%$. The hypokinetic surface increased from $7 \pm 4 \mathrm{~cm}^{2}$ to $11 \pm 6 \mathrm{~cm}^{2}(\mathrm{p}<0.001)$, as did hypokinetic length: $36 \pm 13 \%$ to $44 \pm 16 \%(p<0.001)$. In this group, five out of the eight patients with proximal left anterior descending occlusion developed a typical left ventricular aneurysm. The angiographic results obtained in subgroups 2a (secondary reobstruction, 10 patients) and $2 \mathrm{~b}$ (no recanalisation, 20 patients) are given in Table 2 . The ejection fraction decreased less in subgroup $2 a(52 \pm 8 \%$ to $47 \pm 9 \%$, NS) than in subgroup $2 \mathrm{~b}(55 \pm 10 \%$ to $43 \pm 13 \%, \mathrm{p}<0.001)$. The change in hypokinetic surface was small in subgroup 2a $\left(8 \pm 3 \mathrm{~cm}^{2}\right.$ to $\left.9 \pm 4 \mathrm{~cm}^{2}, \mathrm{NS}\right)$ and large in subgroup $2 \mathrm{~b}\left(7 \pm 5 \mathrm{~cm}^{2}\right.$ to $\left.12 \pm 6 \mathrm{~cm}^{2}, \mathrm{p}<0.001\right)$. Changes in hypokinetic length were similar to those of hypokinetic surface: $34 \pm 11 \%$ to $40 \pm 12 \%(p<0.05)$ in group $2 a, 37 \pm 14 \%$ to $46 \pm 18 \%(p<0.01)$ in group $2 b$.

\section{Comparative study of groups 1 and 2}

The anatomical distribution of the coronary obstruction in groups 1 and 2 was statistically similar except for the number of left anterior descending artery occlusions (15 in group $1 v$ eight in group 2, $\mathrm{p}<0.05$ ). Lesions were more often distal in group 2 than in group 1. This explains the fact that initial global or regional left ventricular function alterations were more severe in group 1 than in group 2 as shown by the ejection fraction $(p<0.01)$, hypokinetic surface $(p<0.001)$, and the hypokinetic length $(p<0.01)$.

Influence of delay between onset of pain and beginning of intracoronary thrombolysis

In group 1 the mean delay was $3.3 \pm 1 \cdot 2$ hours, while it was $4 \cdot 6 \pm 1$ hours in group 2. This difference is significant $(p<0.02)$. No correlation was found, however, between the delay and the percentage change in 
left ventricular function variables.

Three months later, a third left ventricular angiogram and coronary angiogram was obtained in 16 of these 58 patients (seven from group 1 and nine from group 2). Results are given in Table 3. No coronary reocclusion was noted in patients in group 1 but there was one patient with spontaneous recanalisation in those in group 2 . In the patients in group 1 , the percentage residual coronary narrowing decreased from $84 \pm 14 \%$ to $56 \pm 22 \%(p<0.05)$ at the second study and further decreased to $45 \pm 18 \%(p<0.01)$ at the third. Between the second and third studies in group 1, the ejection fraction did not change $(49 \pm 5 \% v 50 \pm 9 \%$, NS) nor did the hypokinetic surface $\left(11 \pm 5 \mathrm{~cm}^{2} v 9 \pm 5\right.$ $\left.\mathrm{cm}^{2}, \mathrm{NS}\right)$ and the hypokinetic length $(44 \pm 14 \% v$ $38 \pm 14 \%$, NS). In group 2 , the ejection fraction further decreased from $47 \pm 11 \%$ to $41 \pm 11 \%(p<0.05)$ but neither the hypokinetic surface $\left(14 \pm 6 \mathrm{~cm}^{2} v\right.$ $\left.11 \pm 4 \mathrm{~cm}^{2}, \mathrm{NS}\right)$ nor the hypokinetic length $(49 \pm 12 \%$ v $49 \pm 12 \%$, NS) was changed.

\section{Discussion}

\section{EFFICACY OF SELECTIVE STREPTOKINASE INFUSION IN CLINICAL ACUTE MYOCARDIAL INFARCTION}

In this series of 80 patients who were considered for intracoronary thrombolysis who underwent early coronary angiography, myocardial infarction was found to be the result of coronary obstruction in all but six cases $(92 \%)$, higher than the figures usually given in the published reports (approximately $80 \%$ in American or German studies). 1415

The progressive recanalisation with streptokinase confirmed the thrombotic nature of the occlusion as seen on coronary angiography. The angiographic aspect of the occlusion during recanalisation was also often suggestive of a thrombus. The failure of intracoronary glyceryl trinitrate in our series as well as in others rules out spasm, as opposed to Olivia and Breckenbridge's ${ }^{16}$ report.

Our $64 \%$ success rate is slightly less than that commonly reported in smaller series, which range from 67\% (Reduto et al. ${ }^{10}$ ) to $81 \%$ (Rutsch et al. ${ }^{12}$ ). Ganz et al. ${ }^{5}$ have even reported a $90 \%$ success rate, which could be explained by the infusion of streptokinase to the immediate vicinity of the clot using a thin catheter inserted through the lumen of the angiography catheter or by the addition of plasmin to streptokinase (thrombolysin) or both.

After recanalisation, the rapid regression of chest pain and the simultaneous return of the ST segment to the isoelectric line mirror the disappearance of ischaemia in the jeopardised myocardium ${ }^{5-9}$ rather than an acceleration of the necrotic process as has been suggested, ${ }^{17}$ which would not accord with the

\section{Cribier, Berland, Champoud, Moore, Behar, Letac}

improvement in regional wall motion after recanalisation.

Myocardial necrosis occurred in every case despite recanalisation, as indicated by the constant appearance of a $Q$ wave on the electrocardiogram and long term persistence of a hypokinetic zone on the left ventricular angiogram. It is probable that only very early recanalisation, probably within 20 to 30 minutes, could totally avoid myocardial infarction, as has been observed when recanalisation was done immediately after an acute obstruction during catheterisation. 1819

In two patients, reobstruction occurred 48 hours after recanalisation at the same site, as was confirmed by a subsequent angiogram. This reocclusion was accompanied by a sharp increase in CK levels, showing that initially an ischaemic zone had been preserved from necrosis by the recanalisation.

\section{COMPLICATIONS}

No accident or incident could be related to the initial left ventricular angiogram performed in all patients except in the case of those in cardiogenic shock.

Reperfusion ventricular arrhythmias; premature ventricular beats, or even episodes of ventricular tachycardia should not actually be considered complications of intracoronary thrombolysis since they were not followed by any adverse effect and were often a sign of successful recanalisation.

In our series, intracoronary thrombolysis had little beneficial effect in patients with cardiogenic shock: eight of 12 such patients died during the procedure, in four of these after a successful revascularisation which could suggest a possible aggravating effect of the recanalisation. In two cases, however, long term survival could, at least in part, be attributed to the recanalisation.

The total dose of streptokinase infused did not exceed $280000 \mathrm{IU}$ in our series, though some authors have used twice that amount. ${ }^{7}$ This could account for the absence of haemorrhagic complications in our series, compared to that reported in a large multicentre study of $7 \cdot 4 \% .^{20}$

\section{LEFT VENTRICULAR FUNCTION AFTER \\ INTRACORONARY THROMBOLYSIS}

The lack of accurate data concerning the natural history of left ventricular function during acute myocardial infarction and the ethical problems involved in randomisation after the initial left ventricular and coronary angiograms make an evaluation of the benefits of recanalisation on myocardial function especially difficult. In other reports, the effects of intracoronary thrombolysis were evaluated by the evolution of the ejection fraction, either immediately or a few weeks later. ${ }^{562122}$ Evaluation of regional wall motion was either subjective ${ }^{22}$ or limited to five 
ventricular zones. ${ }^{21}$ The indices of ventricular function we used after a precise localisation of the hypokinetic zone afford a better appraisal of changes in left ventricular performance.

In our study two groups of patients were compared. Group 1 consisted of all patients in whom recanalisation was achieved and in whom it persisted. Group 2, used as a control group, was more heterogeneous. Of its 30 patients, the 20 in whom recanalisation was unsuccessful (including the five who did not even have infusion of streptokinase) can be considered as real control subjects, while the validity of using as control subjects the 10 patients whose coronary artery reoccluded could be questioned.

Changes in ejection fraction after intracoronary thrombolysis are difficult to assess. During the acute phase of myocardial infarction there is a compensatory hypercontractility of the intact myocardium probably related to increased plasma catecholamines. ${ }^{23}$ This effect could be amplified by afterload reduction with infusion of glyceryl trinitrate, ${ }^{11}$ which was avoided in this study. Therefore the stability of the ejection fraction in group 1 should not be construed as a lack of improvement in left ventricular function. This improvement remains probable if an initial increased ejection fraction value resulting from raised catecholamines is taken into account. For the same reason the significant decrease of ejection fraction in group 2 might be overestimated. Our results are close to those of Rentrop et al.22 but differ from those of Reduto et al. ${ }^{10}$ who found a significantly increased ejection fraction after successful recanalisation on isotopic angiograms, despite a delayed intracoronary thrombolysis, up to 18 hours after the onset of symptoms, in his study. The different method of evaluating left ventricular function could explain this discrepancy.

The almost constant and sometimes striking improvement in the hypokinetic zone in group 1 reflects effective myocardial salvage. It cannot be because of a simple decrease in the systolic expansion of the infarcted zone since the hypokinetic zone deteriorated in the absence of recanalisation (group 2). This view is reinforced by isotopic studies, ${ }^{824} 25$ among them those of Maddahi et al. ${ }^{26}$ who showed a simultaneous increase in left ventricular performance and thallium uptake in the reperfused zone.

In group 2, the deterioration in the hypokinesis led to a ventricular aneurysm in five out of eight patients as opposed to only one out of 15 patients in group 1 , a significant difference $(p<0.02)$. The decrease in the contractility indices was higher in subgroup $2 b$ than in subgroup $2 a$, which suggests a beneficial effect of even temporary recanalisation.

The delay between the onset of pain and intracoronary thrombolysis was longer in group 2 than in group
1. In the latter, however, no relation was found between this delay and the improvement in left ventricular function, in contrast to the findings of Rentrop et al. 22

If myocardial revascularisation cannot completely prevent infarction, our results show that early recanalisation leads to a notable degree of myocardial salvage, as previously shown in experimental studies. ${ }^{1-3}$ The recanalisation seems to "freeze" the extension of the infarction and save the jeopardised myocardium from further and irreversible ischaemia. The absence of a relation between the delay and the left ventricular function changes may seem paradoxical, but the exact time at which the artery is occluded is not really known. In addition the collateral flow was not investigated in this study where the initial angiogram was limited to the infarct related coronary artery.

The small number of patients in the third study does not allow us to draw any conclusion as to the stability of the changes in regional left ventricular function variables observed at the second, except for the further decrease in ejection fraction in group 2. There was, however, a tendency towards an improvement of the hypokinesia in group 1 which could become significant with a few more patients.

If the improvement of regional left ventricular function after successful recanalisation confirms a partial salvage of jeopardised myocardium, the relatively small number of patients and the brief period of the survey do not allow us to draw conclusions on the effects of recanalisation on long term mortality and morbidity though there were no hospital deaths among the patients in whom recanalisation was successful and two among those in whom it was not. One must also bear in mind the remarkable reduction in hospital mortality in the German multicentre study which included over 200 patients. ${ }^{20}$

Management following recanalisation is difficult when a severe stenosis persists, which is almost always the case. In this series, only three patients had an aortocoronary bypass performed to the recanalised artery after the second study. The decision to operate was only taken when there were multiple coronary lesions, when regional left ventricular function was satisfactory, and when the distal bed of the recanalised artery was of good quality. Merx et al ${ }^{20}$ reported an early reocclusion rate of $20 \%$. In our study, the reocclusion rate was $26 \%$ at the second study. These figures suggest that after recanalisation coronary bypass should be undertaken whenever possible, as Mathey et $a l .^{21}$ have tried with good results. Alternatively immediate or delayed transluminal angioplasty might be attempted, ${ }^{21} 27$ though a better knowledge of the spontaneous evolution of residual coronary stenosis after recanalisation seems to be necessary in the light of our results. Further long term follow up 
studies are needed.

We thank William Ganz for his critical review of the manuscript.

\section{References}

1 Baughman KL, Maroko PR, Vatner SF. Effects of coronary artery reperfusion on myocardial infarct size and survival in conscious dogs. Circulation 1981; 63: 317-23.

2 Costantini C, Corday E, Lang TW, et al. Revascularization after 3 hours of coronary arterial occlusion: effects on regional cardiac metabolic function and infarct size. Am f Cardiol 1975; 36: 368-84.

3 Reimer KA, Lowe JE, Rasmussen M, Jennings RB. The wavefront phenomenon of ischemic cell death. 1 . Myocardial infarct size vs duration of coronary occlusion in dogs. Circulation 1981; 56: 786-94.

4 Rentrop P, Blanke H, Wiegand V, Koestering H, Oster $R$, Leitz K. Acute myocardial infarction: intracoronary application of nitroglycerin and streptokinase in combination with transluminal recanalization. Clin Cardiol 1979; 2: 354-63.

5 Ganz W, Buchbinder N, Marcus H, et al. Intracoronary thrombolysis in evolving myocardial infarction. $\mathrm{Am}$ Heart 7 1981; 101: 4-13.

6 Cowley MJ, Hastillo A, Vetrovec GW, Hess ML. Effects of intracoronary streptokinase in acute myocardial infarction. Am Heart f 1981; 102: 1149-58.

7 Lee G, Amsterdam EA, Low R, et al. Efficacy of percutaneous transluminal coronary recanalization utilizing streptokinase thrombolysis in patients with acute myocardial infarction. Am Heart ff 1981; 102: 1159-67.

8 Markis JE, Malagold M, Parker JA. et al. Myocardial salvage after intracoronary thrombolysis with streptokinase in acute myocardial infarction. Assessment by intracoronary thallium-201. $N$ Engl f Med 1981; 305: 777-82.

9 Mathey DG, Kuck KH, Tilsner V, Krebber HJ, Bleifeld W. Nonsurgical coronary artery recanalization in acute transmural myocardial infarction. Circulation 1981; 63: 489-97.

10 Reduto LA, Freund GC, Gaeta JM, Smalling RW, Lewis $B$, Gould $\mathrm{KL}$. Coronary artery reperfusion in acute myocardial infarction: beneficial effects of intracoronary streptokinase on left ventricular salvage and performance. Am Heart f 1981; 102: 1168-77.

11 Rentrop P, Blanke H, Karsch KR, Kaiser H, Köstering $H$, Leitz K. Selective intracoronary thrombolysis in acute myocardial infarction and unstable angina pectoris. Circulation 1981; 63: 307-17.

12 Rutsch W, Schartl M, Mathey D, et al. Percutaneous transluminal coronary recanalization: procedure, results, and acute complications. Am Heart $\mathcal{f}$ 102; 102: 1178-81.

13 Leighton RF, Witt SM, Lewis RP. Detection of hypokinesis by a quantitative analysis of left ventricular cineangiograms. Circulation 1974; 50: 121-7.

14 Mason DT. International experience with percutaneous transluminal coronary recanalization by streptokinasethrombolysis reperfusion in acute myocardial infarction: new, safe, landmark therapeutic approach salvaging ischemic muscle and improving ventricular function. Am Heart f 102; 102: 1126-33.

15 De Wood MA, Spores J, Notske R, et al. Prevalence of total coronary occlusion during the early hours of transmural myocardial infarction. $N$ Engl f Med 1980; 303: 897-902.

16 Oliva PB, Breckenridge JC. Arteriographic evidence of coronary arterial spasm in acute myocardial infarction. Circulation 1977; 56: 366-74.

17 Sobel BE, Bergmann SR. Coronary thrombolysis: some unresolved issues. Am $\mathcal{F}$ Med 1982; 72: 1-4.

18 Rentrop P, De Vivie ER, Karsch KR, Kreuzer H. Acute coronary occlusion with impending infarction as an angiographic complication relieved by a guidewire recanalization. Clin Cardiol 1978; 1: 101-6.

19 Cribier A, Berland J, Brunhes G, Richard C, Letac B. Acute coronary occlusion during coronary angiography in two cases. Br Heart $\mathcal{F}$ 1982; 47: 244-8.

20 Merx W, Dörr R, Rentrop P, et al. Evaluation of the effectiveness of intracoronary streptokinase infusion in acute myocardial infarction: postprocedure management and hospital course in 204 patients. Am Heart $\mathcal{F}$ 1981; 102: 1181-7.

21 Mathey DG, Rodewald G, Rentrop P, et al. Intracoronary streptokinase thrombolytic recanalization and subsequent surgical bypass of remaining atherosclerotic stenosis in acute myocardial infarction: complementary combined approach effecting reduced infarct size, preventing reinfarction, and improving left ventricular function. Am Heart f 1981; 102: 1194-1201.

22 Rentrop P, Blanke H, Karsch KR, et al. Changes in left ventricular function after intracoronary streptokinase infusion in clinically evolving myocardial infarction. $\mathrm{Am}$ Heart f 1981; 102: 1188-93.

23 Wallace AG. Catecholamine metabolism in patients with acute myocardial infarction. In: Julian DG, Oliver MF, eds. Acute myocardial infarction. Edinburgh \& London: Livingstone, 1968: 237.

24 Schuler G, Schwarz F, Hofmann M, et al. Thrombolysis in acute myocardial infarction using intracoronary streptokinase: assessment by thallium-201 scintigraphy. Circulation 1982; 66: 658.

25 Schwarz F, Schuler G, Katus H, et al. Intracoronary thrombolysis in acute myocardial infarction: correlations among serum enzyme, scintigraphic and hemodynamic findings. Am $\mathcal{F}$ Cardiol 1982; 50: 32-8.

26 Maddahi J, Ganz W, Ninomiya K, et al. Myocardial salvage by intracoronary thrombolysis in evolving acute myocardial infarction: evaluation using intracoronary injection of thallium-201. Am Heart f 1981; 102: 664-74.

27 Goldberg S, Urban PL, Greenspon A, Lebenthal M, Walinsky P, Maroko P. Combination therapy for evolving myocardial infarction: intracoronary thrombolysis and percutaneous transluminal angioplasty. $A m \mathcal{F} \mathrm{Med}$ 1982; 72: 994-7.

Requests for reprints to Dr Alain Cribier, Service de Cardiologie, Hôpital Charles Nicolle, 1 rue de Germont, 76031 Rouen-Cedex, France. 